\title{
Clinical Response of Azithromycin as an Adjunct to Non-Surgical Periodontal Therapy in Smokers
}

\author{
Paulo Mascarenhas, ${ }^{*}$ Ricardo Gapski, ${ }^{\dagger}$ Khalaf Al-Shammari, ${ }^{\ddagger}$ Roger Hill, * Stephen Soehren, * \\ J. Christopher Fenno, $§$ William V. Giannobile, *\| and Hom-Lay Wang*
}

Background: Antibiotic therapy can be used in very specific periodontal treatment situations such as in refractory cases of periodontal disease found to be more prevalent in smokers. This study was designed to determine the efficacy of azithromycin (AZM) when combined with scaling and root planing (SRP) for the treatment of moderate to severe chronic periodontitis in smokers.

Methods: Thirty-one subjects were enrolled into a 6-month randomized, single-masked trial to evaluate clinical, microbial (using benzoyl-DL-arginine naphthylamine [BANA] assay), and gingival crevicular fluid (GCF) pyridinoline cross-linked carboxyterminal telopeptide of type I collagen (ICTP) levels in response to SRP alone or SRP + AZM. At baseline, patients who smoked $\geq 1$ pack per day of cigarettes who presented with at least five sites with probing depths (PD) of $\geq 5 \mathrm{~mm}$ with bleeding on probing (BOP) were randomized into the test or control groups. At baseline and 3 and 6 months, clinical measurements (probing depth [PD], clinical attachment loss [CAL], and bleeding on probing $[\mathrm{BOP}]$ ) were performed. GCF bone marker assessment (Ctelopeptide [ICTP] as well as BANA test analyses) were performed at baseline, 14 days, and 3 and 6 months.

Results: The results demonstrated that both groups displayed clinical improvements in PD and CAL that were sustained for 6 months. Using a subject-based analysis, patients treated with SRP + AZM showed enhanced reductions in PD and gains in CAL at moderate (4 to $6 \mathrm{~mm}$ ) and deep sites $(>6 \mathrm{~mm})(P<0.05)$. Furthermore, SRP $+\mathrm{AZM}$ resulted in greater reductions in BANA levels compared to SRP alone $(P<0.05)$ while rebounds in BANA levels were noted in control group at the 6-month evaluation. No statistically significant differences between groups on mean BOP and ICTP levels during the course of the study were noted.

Conclusions: The utilization of AZM in combination with SRP improves the efficacy of non-surgical periodontal therapy in reducing probing depth and improving attachment levels in smokers with moderate to advanced attachment loss. J Periodontol 2005;76:426-436.

\section{KEY WORDS}

Azithromycin/therapeutic use; comparison studies; periodontitis/ drug therapy; periodontitis/therapy; planing; scaling; smoking/ adverse effects.

\footnotetext{
* Department of Periodontics/Prevention/Geriatrics, School of Dentistry, University of Michigan, Ann Arbor, MI.

$\dagger$ Previously, Department of Periodontics/Prevention/Geriatrics, School of Dentistry, University of Michigan; currently, Department of Periodontics, University of Missouri at Kansas City, Kansas City, MO.

† Previously, Department of Periodontics/Prevention/Geriatrics, School of Dentistry, University of Michigan; currently, Ministry of Health, Kuwait City, Kuwait.

$\S$ Department of Biologic and Materials Science, School of Dentistry, University of Michigan.

|| Department of Biomedical Engineering, University of Michigan.
}

$T$ The efficacy of scaling and root planing (SRP) as a part of the non-surgical treatment of chronic periodontitis has been established through several longitudinal studies of periodontal therapy. ${ }^{1-3}$ Thorough root debridement has been proposed as the key determinant for the success of periodontal treatment. ${ }^{1,4}$ However, several anatomical factors, such as furcations and deep pockets, have been suggested to limit the effectiveness of non-surgical periodontal therapy. ${ }^{1,5}$ In addition, penetration of bacteria deep into gingival tissues or even in the dentinal tubules impairs the overall results of nonsurgical treatment. Surgical procedures have been proposed to provide better access for root debridement, but long-term results have not shown convincing superiority over non-surgical treatment modalities ${ }^{2,3,6,7}$ especially in smokers. ${ }^{8-10}$

Smoking has been demonstrated to be one of the major risk factors for periodontitis. ${ }^{11,12}$ Current smokers have frequently more severe periodontal disease than never smokers or past smokers, and have a higher prevalence of subgingival sites colonized with red and orange complex bacterial species. ${ }^{13,14}$ Smokers are also associated with less favorable therapeutic responses to both nonsurgical and surgical therapy than non-smokers $9,10,15-21$ and were more frequently associated with 
periodontal disease rebound or recurrence. ${ }^{22}$ There is a fairly well established biologic rationale for the negative effects of cigarette smoking on periodontal tissues. These include: 1) immunosuppressive effect on the host, adversely affecting host-parasite interactions; ${ }^{23} 2$ ) impaired peripheral blood polymorphonuclear leukocyte motility, chemotaxis, and phagocytosis; ${ }^{24}$ 3) decreased antibody production; ${ }^{25} 4$ ) alterations in the subgingival vascular oxygen tension;26,27 5) increased adhesion of bacteria to epithelial cells;28 6 ) reduced proliferation, migration, and attachment of fibroblast to the root surface, ${ }^{29,30}$ and 7) impaired collagen synthesis and protein secretion. ${ }^{31}$

Although periodontal treatment outcomes are predictable and are able to establish and maintain periodontal health for long periods of time, ${ }^{32}$ it has been reported that between $4 \%$ and $8 \%$ of periodontal patients respond poorly to conventional non-surgical, surgical, and maintenance therapy. ${ }^{33-38}$ In this group of patients, deep pockets that remain after periodontal treatment serve as "reservoirs" of pathogens for future infections, which lead to recurrent disease situations. ${ }^{39}$

Because of the presence of anaerobic pathogens in the periodontally diseased sites of "refractory periodontitis" patients, ${ }^{40}$ the adjunctive use of antibiotics may be needed to control this type of disease. ${ }^{32,41}$ It is also believed that the reduction in the periodontal pathogens leads to a shift in the host-parasite balance, which may help in long-term disease control efforts. ${ }^{42}$

The rationale for the use of antimicrobial agents as adjuncts in periodontal therapy is based on the premise that periodontal disease is an infection caused by groups of specific microorganisms associated to certain host genetic characteristics. ${ }^{43}$ These groups of bacteria are commonly organized in clusters or complexes, often present in periodontal diseased sites. ${ }^{44}$ In theory, selected antibiotic agents possessing activity against anaerobic bacterial species should prove beneficial in periodontal therapy, since the majority of periodontal infections are associated with such specific periodontopathogens. ${ }^{45-46}$ These include both systemic and locally delivery antibiotics that contain antibiotics such as tetracycline, doxycycline, minocycline and others. These agents have shown promising outcomes in augmenting the results of mechanical therapy. ${ }^{47-48}$

One possible antibiotic to use as an adjuvant to periodontal therapy could be azithromycin (AZM). AZM, a macrolide called azalides, has a better oral absorption than other antibiotics in the same group because of its higher resistance to gastric acids. ${ }^{49}$ This antibiotic is known to be effective against several systemic infections as well as intraoral infections. ${ }^{50-52}$ Among its interesting characteristics are a higher tissue concentration (100 times higher than serum AZM concentration), ${ }^{53}$ and that it is preferentially taken up by phagocytes; therefore, its levels in infected tissues are much higher than non-infected sites. ${ }^{54}$ AZM antimicrobial efficacy against periodontal pathogens (e.g., Porphyromonas gingivalis, Actinobacillus actinomycetemcomitans) has also been studied. ${ }^{51,52,55}$

The aim of this randomized, single-masked, controlled clinical trial study was to determine if the use of azithromycin improves the outcomes obtained in combination with non-surgical periodontal treatment in smokers.

\section{MATERIALS AND METHODS}

This study was designed as a single center, singlemasked, randomized parallel trial of AZM in smokers with moderate to advanced chronic periodontitis.

A written informed consent form was provided for individuals willing to participate in this trial who met the inclusion and exclusion criteria outlined in a protocol approved by the University of Michigan Institutional Review Board. All patients completed a health history questionnaire to insure that they were medically qualified for participation in the study. Inclusion criteria included patients 30 years old or older who smoked at least one pack of cigarettes a day for more than 5 years and had at least 10 teeth in the functional dentition excluding third molars. All patients had to have at least six sites with periodontal pockets and attachment loss of $5 \mathrm{~mm}$ with bleeding on probing.

Thirty-one patients qualified for the study. Full mouth clinical measurements were recorded. Microbiological and GCF samples were collected for ICTP analyses. Patients were scheduled within 2 weeks for two sessions of scaling and root planing (SRP) which were performed using ultrasonic scalers and hand instrumentation. Patients were advised not to use any kind of mouthwash or rinse during the study period. Oral hygiene instructions were given at both SRP appointments, followed by demonstrations.

At the end of the second SRP appointment, patients were randomly assigned to one of the two study groups. An independent study coordinator, unaware of treatment procedure, selected test or control designations from a bag to determine group assignments. Both examiner and treating clinician were masked to patient assignment.

The 15 assigned to the AZT + SRP (test) group received the study drug for 5 days (two $250 \mathrm{mg}$ tablets the first day and one $250 \mathrm{mg}$ tablet for each of the next 4 days). Tablets were taken 1 hour before or two hours after a meal. The 16 control group patients received no drug.

The same examiner performed all measurements at all time points. The examiner was calibrated to minimize intra-examiner variability (kappa statistic $\geq 90 \%$ ). The examiner also provided periodontal maintenance treatment at 3 and 6 months.

\section{Full-Mouth Manual Probing Measurements}

Probing depth (PD), clinical attachment level (CAL), and bleeding on probing (BOP) were assessed for all teeth 
(excluding third molars) in all patients at baseline and months 3 and 6 . All measurements were performed using calibrated manual probes. ${ }^{\#}$ PD and CAL were measured at six sites per tooth.

\section{Trypsin-Like Enzyme Activity Monitoring}

Microbiological monitoring was performed at baseline, day 14, and months 3 and 6 . A pick** was used for the BANA test. ${ }^{\dagger \dagger} \mathrm{A}$ separate toothpick was used for each site (the same four sites used for GCF analysis plus two more also with $\mathrm{PD} \geq 5 \mathrm{~mm}$ and positive to BOP). After with-

Table I.

\section{Mean Baseline Clinical Characteristics of Study Groups}

\begin{tabular}{lccc}
\hline & Control $(\mathrm{N}=15)$ & Test $(\mathrm{N}=15)$ & $\begin{array}{c}\text { P Value } \\
\text { (Mann-Whitney) }\end{array}$ \\
\hline Age (years) & $45.34 \pm 10.75\left(31-66^{*}\right.$ & $47 \pm 10.06\left(33-64^{*}\right.$ & NS \\
Gender $(\%$ males $)$ & 53.34 & 73.34 & NS \\
PD (mm) & $3.51 \pm 0.67$ & $4.23 \pm 0.82$ & 0.01 \\
CAL (mm) & $3.92 \pm 0.97$ & $5.02 \pm 1.50$ & 0.02 \\
ICTP (pg/site) & $206.90 \pm 98.84$ & $200.30 \pm 117.45$ & NS \\
\% BOP & $67.27 \pm 18.35$ & $59.30 \pm 27.92$ & NS \\
\% BANA positive & $47.74 \pm 37.72$ & $52.19 \pm 36.65$ & NS \\
\hline
\end{tabular}

* Range.

drawing the toothpick, the adherent plaque was placed onto the BANA-impregnated strip at the lower edge of a four-sample reagent card. An upper reagent strip containing Evan's black dye was then activated through dampening with distilled water and the two strips were folded to contact each other. The card was then inserted into a heating block and incubated for 5 minutes at $35^{\circ} \mathrm{C}$, a time and temperature protocol which gives the optimal balance of sensitivity and specificity for the BANA test when screening patients of unknown periodontal status. ${ }^{56}$ Naphthylamine released due to the presence of any of the BANA-hydrolyzing bacterial species (Tannerella forsythensis, Porphyromonas gingivalis, and Treponema denticola) will diffuse into the upper reagent strip where it reacts with the Evans black dye to form a permanent blue-black color. Signals were recorded as: 0 , not detected; 1 , weak-positive; and 2 , positive.

\section{Gingival Crevicular Fluid (GCF) Sampling}

GCF was collected from four sites (PD $>4 \mathrm{~mm}$ with BOP) in each patient at baseline, day 14 , and months 3 and 6 for ICTP analysis. ${ }^{57}$ The frozen samples were thawed at room temperature, followed by elution of proteins by microcentrifugation using $100 \mu \mathrm{l}$ of a solution of $\mathrm{pH} 7.4$ phosphate-buffered saline containing $15 \mathrm{nM}$ aprotinin, ${ }^{\ddagger} \neq 1 \mathrm{mM}$ phenylmethylsulfonylfluoride (PMSF), ${ }^{\neq \dagger}$ and $0.1 \%$ human serum albumin. The eluates containing the ICTP were then pipetted to $12 \times$ $75 \mathrm{ml}$ polypropylene tubes to allow incorporation of the primary antiserum ICTP. This was followed by addition of a radioactive tracer of $\mathrm{I}^{125}$ which was incubated for 2 hours at $37^{\circ} \mathrm{C}$. Following the incubation, a preprecipitated secondary antibody complex was added to separate the bound from free tracer and allowed to incubate at room temperature for 30 minutes, followed by centrifugation at 3,000 RPM for 30 minutes. The supernatant was then discarded and the remaining pellet measured by a gamma counter.

\section{Statistical Analysis}

The results of this study were compared between treatment groups with respect to demographic background information (age and gender) and efficacy parameters (BOP, PD, CAL). Data were first averaged within each patient, and then patient means were analyzed between treatment groups to determine baseline comparability of the two groups. Differences between study drug and control groups were performed using the Student $t$ test. Differences with a $P$ value $<0.05$ were considered significant.

Primary efficacy analyses at each post-baseline visit were based on data stratified according to baseline probing depth of $<4,4$ to 6 , and $>6 \mathrm{~mm}$ and averaged in a subject and across subjects for probing depth and clinical attachment levels. ICTP levels and percent and levels of BANA were not stratified based on initial probing depth since all sampled sites for these parameters had $P D \geq 5 \mathrm{~mm}$. These parameters were also averaged in a subject and then across subjects for further analysis. The means and standard deviations for all the variables studied were computed for each examination period. Analysis of variance (ANOVA) and co-variance including repeated measures were performed on all data at baseline, 14 days (for ICTP and BANA test only), 3 and 6 months to detect significant differences from the control group and from the baseline values. The post hoc Scheffé multiple range test was used to identify which means were significantly different from control and baseline. The range test was performed only if the overall $F$ test for the ANOVA was significant at the 0.05 level.

\section{RESULTS}

Table 1 presents mean baseline clinical characteristics. There were no statistically significant differences between

\footnotetext{
\# Model UNC-15, Hu-Friedy Manufacturing Co., Inc., Chicago, IL.

* * Stim-U-Dent, Johnson and Johnson, Windsor, NJ.

$\dagger \dagger$ Perioscan, Oral B, Redwood City, CA.

キ巿 Sigma Chemical Company, St. Louis, MO.
} 
groups regarding age and gender at baseline. In addition, no significant differences were noted between the treatment groups with respect to baseline BOP, percent BANA positive sites and ICTP levels, although statistically significant differences between both studied groups were observed for the mean PD and $\operatorname{AL}(P=0.01$ and $P=0.02$, respectively).

All 15 patients in the test group (although one patient did quit smoking after 2 months) and 15 of the 16 control patients (one decided to have periodontal treatment outside the study protocol and exited) completed the study for a drop-out rate of $3.2 \%$. All 15 patients in the test group took all six tablets (100\% compliance). The compliance was determined by answered questionnaires and pill count.

\section{Full-Mouth Clinical Measurements (all PD strata)}

The mean per-patient average change in PD and CAL from baseline is shown in Figures 1 and 2. Both control and test groups demonstrated a statistically significant reduction in PD $(0.45$ and $1.33 \mathrm{~mm}$, respectively, $P<0.05)$ and CAL gain $(0.46$ and $1.13 \mathrm{~mm}$, respectively, $P<0.05)$ compared to baseline; however, even though the patients were randomly assigned for each one of the two groups, at baseline there was a statistically significant difference (Table 1 ) in the PD (3.51 and $4.23 \mathrm{~mm}$ for control and test group, respectively) and CAL (3.92 and $5.02 \mathrm{~mm}$ for control and test groups, respectively). The major variation in the group differences was in the 1 to $3 \mathrm{~mm}$ and 4 to $6 \mathrm{~mm}$ stratum; there were no significant differences in the baseline PD or CAL in the $\geq 6 \mathrm{~mm}$ stratum. For the PD values, these differences were not present for the 3 and 6 month evaluation time points, representing a greater PD reduction for the test group. As illustrated on Figure 3 , the percentage of BOP for all sites and for both the test and control groups demonstrated a statistically significant reduction from baseline to 3 months. This reduction was sustained for the duration of the study $(17.71 \%$ and $18.6 \%$ for the control and test groups, respectively).

Shallow sites (baseline $<4 \mathrm{~mm}$ ). Figure 4 shows the mean per-patient change in PD from baseline to 6 months for initial PD 1 to $3 \mathrm{~mm}$. The data demonstrate that both control and test groups showed a reduction in PD compared to baseline (0.02 and $0.43 \mathrm{~mm}$, respectively), a difference that was statistically significant for the AZM group at both the 3 and 6 months time points compared to baseline $(P<0.05)$. The test group showed a statistically significant CAL gain $(0.55$ versus $0.11 \mathrm{~mm})$. A statistically significant difference $(P<0.05)$ between groups was only identified at baseline (Fig. 5).

Moderate sites (baseline PD 4 to $6 \mathrm{~mm}$ ). Mean perpatient changes in full mouth PD and CAL levels from baseline with an initial PD of 4 to $6 \mathrm{~mm}$ are shown in Figures 6 and 7, respectively. Consistent with results from

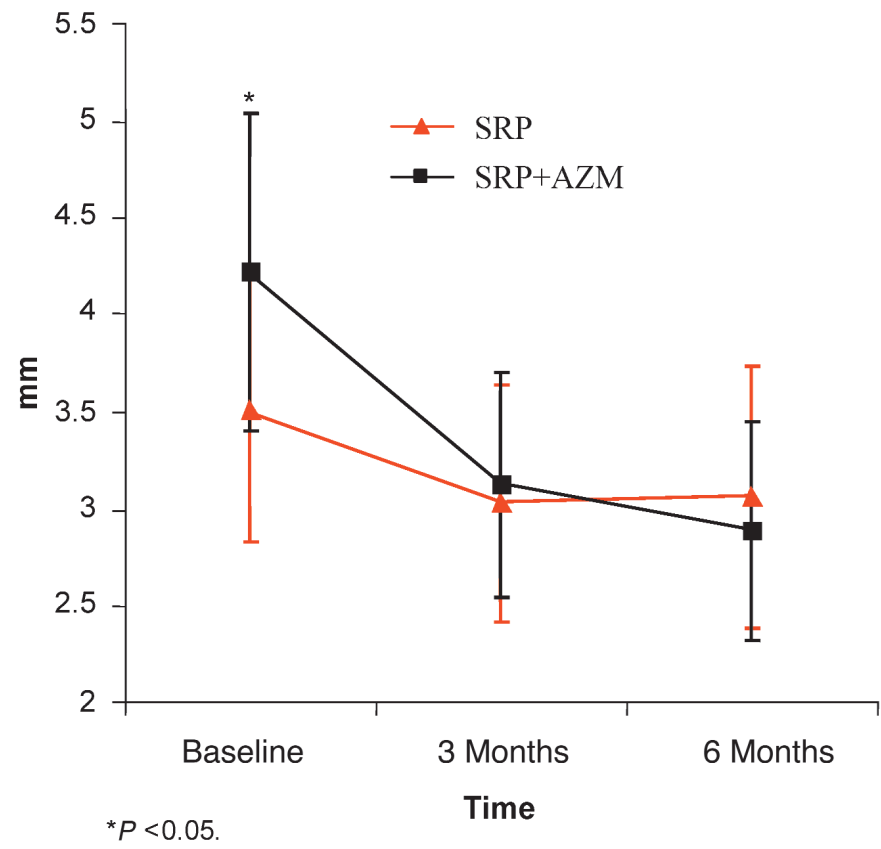

Figure I.

Mean per patient full-mouth probing depths $(\mathrm{mm})$ for $A Z M+S R P$ or SRP. Data expressed as means \pm SE. *P $<0.05$ represents a statistically significant difference between groups at baseline.

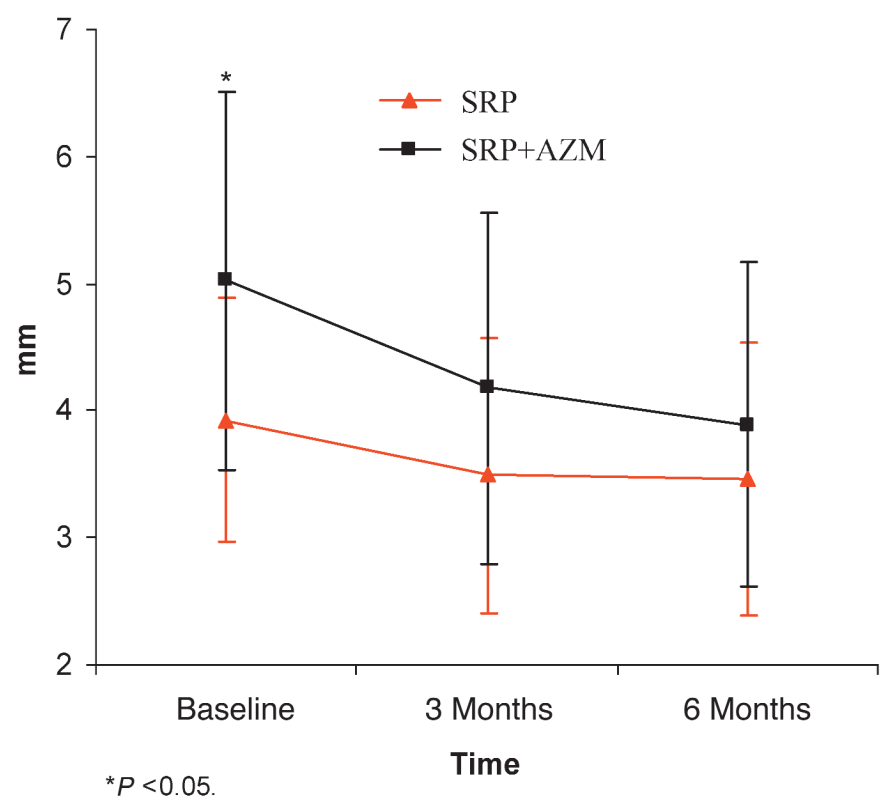

Figure 2.

Mean per patient full-mouth clinical attachment levels $(\mathrm{mm})$ for AZM + SRP or SRP. Data expressed as means $\pm S E$. *P $<0.05$ represents a statistically significant difference between groups at baseline.

pooled PD strata there were statistically significant reductions in PD and gains in CAL compared to baseline for both test and control groups. Specifically for the 


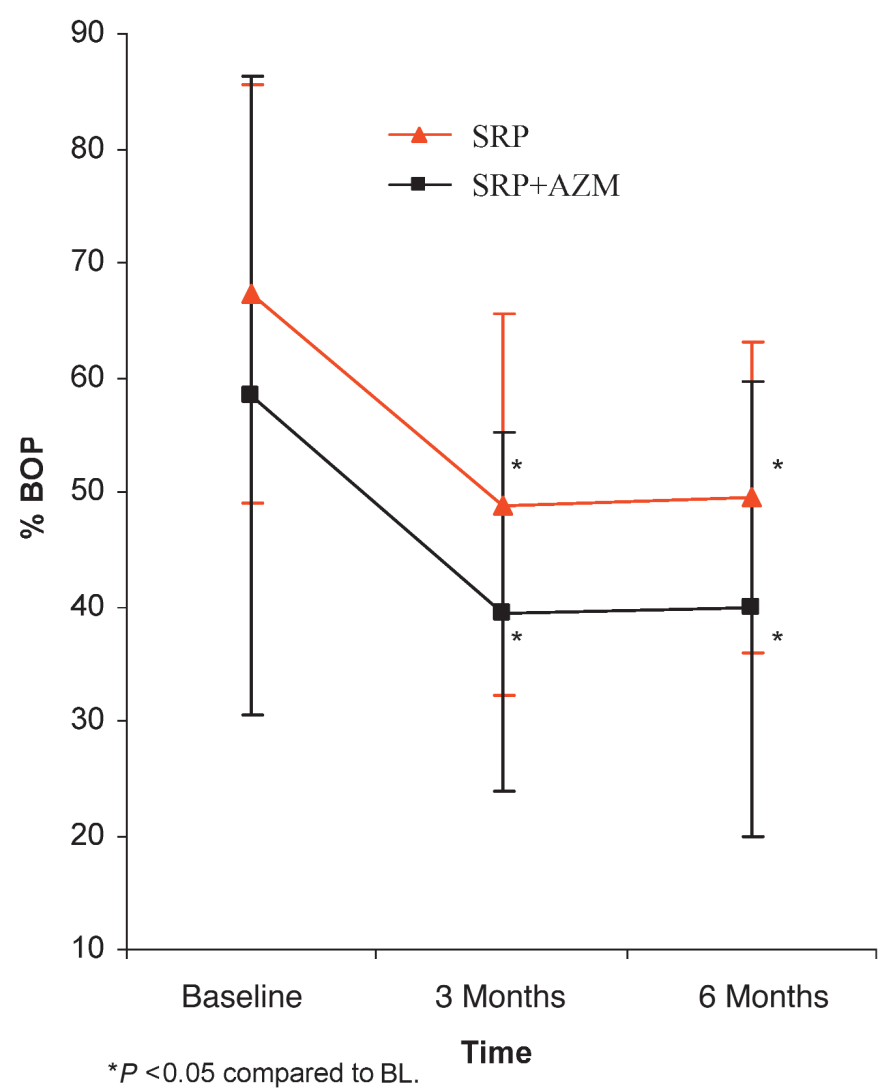

Figure 3.

Mean per patient full-mouth bleeding on probing for AZM + SRP or SRP. Data expressed as percent of means $\pm S E$.

PD changes (Fig. 6), there was a statistically significant difference between groups for the reduction at 6 months (1.0 and $1.7 \mathrm{~mm}$ for control and test groups, respectively, $P<0.05)$. CAL levels were statistically different between groups at baseline $(4.95$ and $5.47 \mathrm{~mm}$, $P<0.05)$ but were identical at 6 months $(1.01$ versus $1.52 \mathrm{~mm}$ ). Both groups revealed statistically significant reduction at 3 and 6 months compared to baseline.

Deep sites (baseline PD $>6 \mathrm{~mm}$ ). Figures 8 and 9 show the mean per-patient changes in PD and CAL, respectively. When compared to shallow pockets this PD stratum showed greater PD reductions for both test and control groups. Drug therapy resulted in a greater reduction of PD in deep sites compared to controls ( 3.52 versus $1.98 \mathrm{~mm}, P<0.05$ ), and this difference was sustained for the duration of the study. CAL changes were larger for the test group compared to the control and the differences were significantly different at 6 months ( 2.56 versus $1.32 \mathrm{~mm}, P<0.05$ ). In addition, patients receiving the drug showed a trend increase CAL gain at 6 months while control group showed almost no further gain after 3 months (Fig. 9). Both groups revealed statistically significant CAL gains at 3 and 6 months compared to baseline.

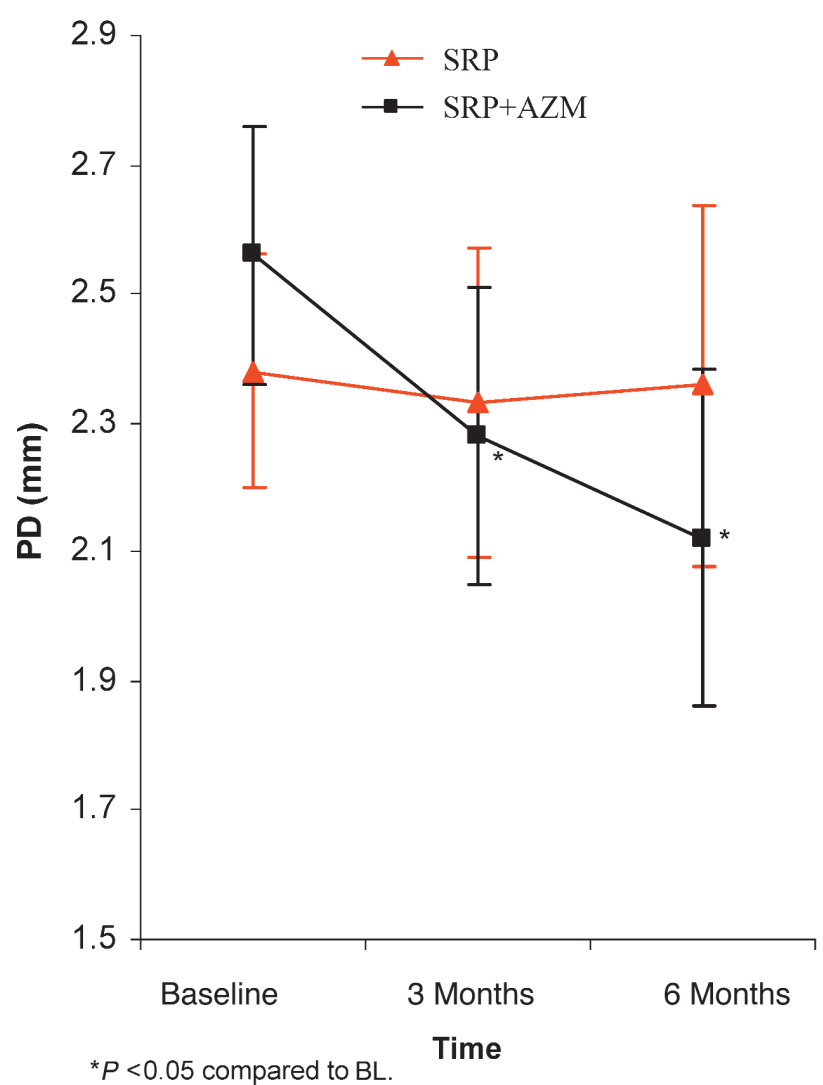

Figure 4.

Effect of AZM + SRP or SRP on PD for shallow sites (PD $<4 \mathrm{~mm})$. Data expressed as per patient means \pm SE.

\section{Distribution of Sites Losing Attachment}

The percentage of sites losing $\geq 2 \mathrm{~mm}$ CAL were similar in both groups $(1.2 \%$ and $1.3 \%$ for control and test group, respectively, $P>0.05)$.

\section{BANA Outcomes}

The mean per patient and group percentage of BANA positive sites were analyzed, as well as the mean BANA values for all pockets. There was an immediate reduction in the BANA positive species in both drug and control groups after SRP (Fig. 10). The percentage of BANA positive sites rebounded to the baseline level in the control group at 3 and 6 months; however, in the drug group the reduction was significantly sustained $(P<0.05)$ at both time points. Overall, $3.35 \%$ and $33.32 \%$ reduction on BANA positive sites were detected for the control and test group respectively $(P<0.05)$. Similar results were also observed when mean BANA values were analyzed (Fig. 11).

\section{ICTP}

Figure 12 shows that ICTP mean values were reduced in both groups after baseline evaluation. The observed reduction was statistically different from baseline at 


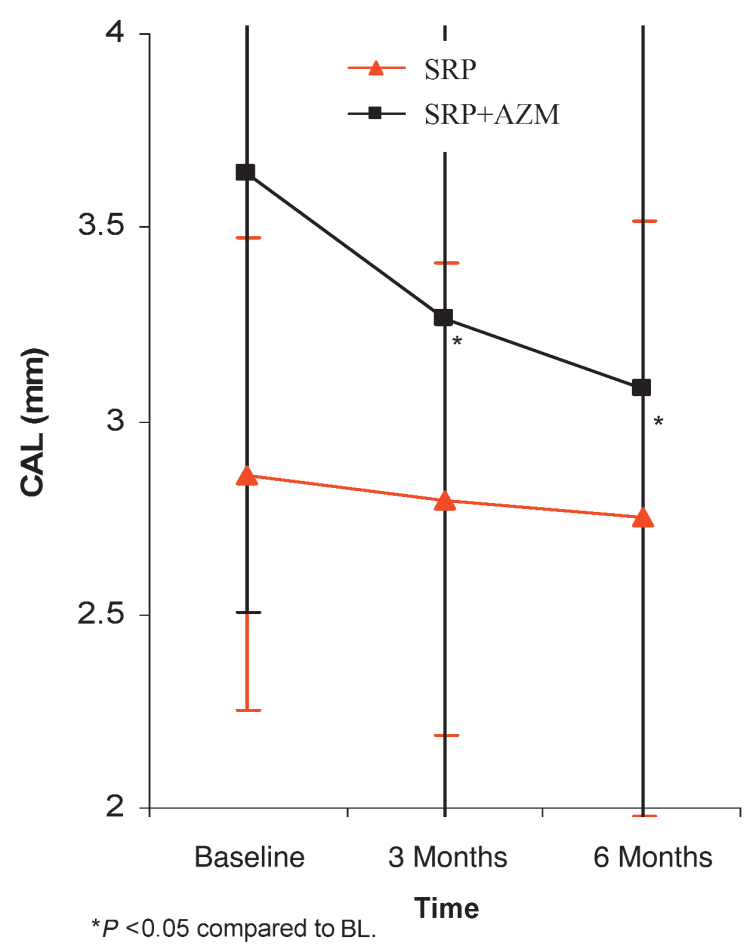

Figure 5.

Effect of AZM + SRP or SRP on CAL for shallow sites (PD $<4 \mathrm{~mm}$ ). Data expressed as per patient means $\pm S E$.

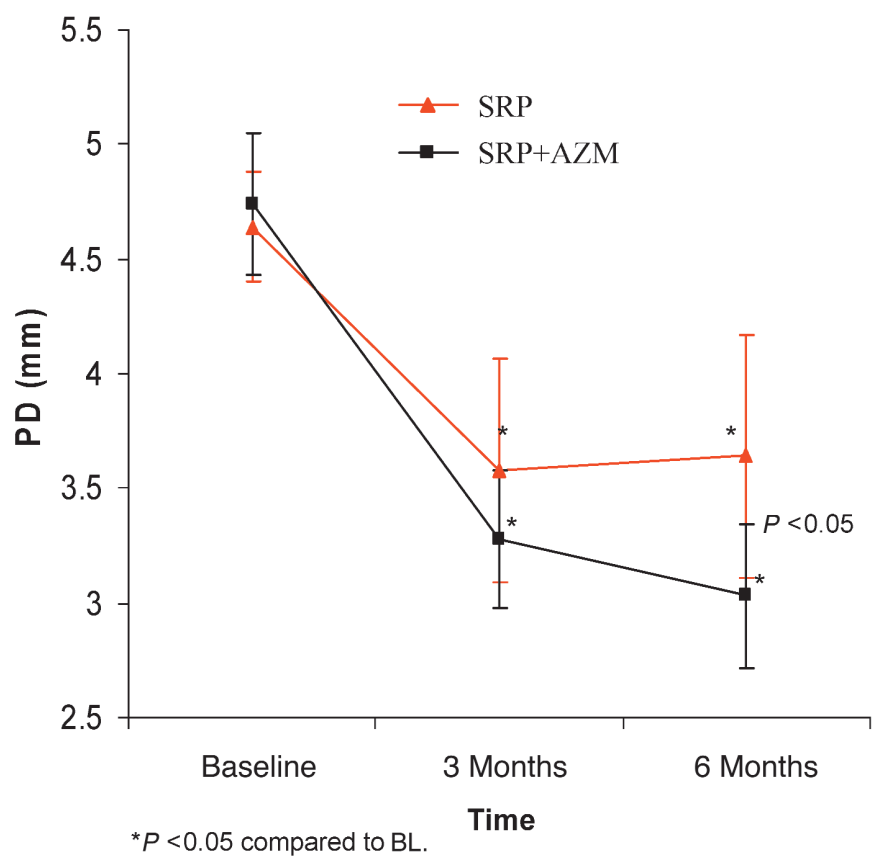

Figure 6.

Effect of AZM + SRP or SRP on PD for moderate sites (PD 4 to $6 \mathrm{~mm}$ ). Data expressed as per patient means \pm SEM. $P<0.05$ represents a statistically significant difference between groups at month 6 .

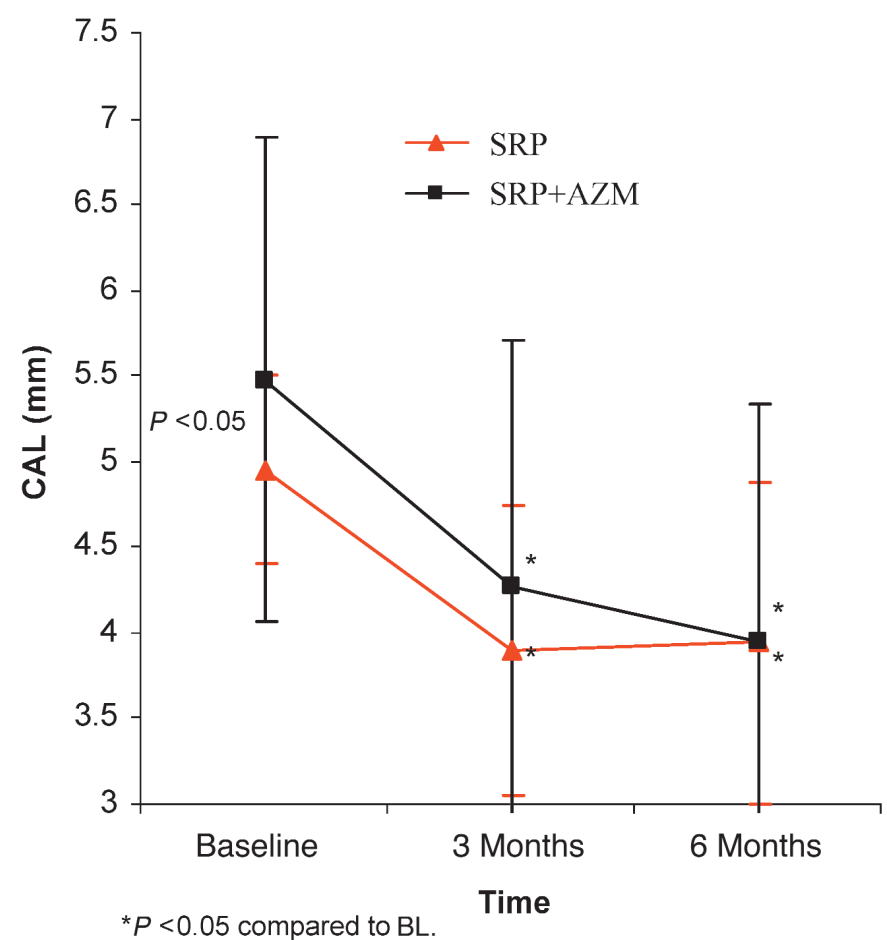

Figure 7.

Effect of AZM + SRP or SRP on CAL for moderate sites (PD 4 to $6 \mathrm{~mm}$ ). Data expressed as per patient means $\pm S E$. $P<0.05$ represents a statistically significant difference between groups at baseline.

the 14-day and 6-month time points, and was slightly greater for test group but the difference did not reach a statistically significant level. At the 6 -month evaluation, the reduction in ICTP was $65.9 \mathrm{pg} / \mathrm{site}$ in the control group compared to $87.5 \mathrm{pg} / \mathrm{site}$ in the test group. For both groups, the ICTP reduction at 3 months was not statistically significant compared to baseline $(P>0.05)$. ICTP values observed in sites with PD $\geq 7 \mathrm{~mm}$ were higher than in the shallower sites ( 4 to $6 \mathrm{~mm}$ ), and were not statistically different.

\section{DISCUSSION}

Periodontal therapy is focused on the restoration and maintenance of the periodontium in a state of health, function, and esthetics. That can be achieved with an initial therapy or the hygienic phase of periodontal treatment. ${ }^{2,3,6}$ In such cases systemic antibiotics like AZM may be used in order to enhance the success rate of periodontal therapy. ${ }^{51,58}$ AZM has been found useful in the treatment of odontogenic and periodontal infections, ${ }^{50,58-61}$ because of its increased acid stability, increased distribution, decreased binding to plasma proteins, and rapid absorption. ${ }^{62,63}$ Other important characteristics of this drug are the increased concentration found in cells such as neutrophils, ${ }^{64}$ macrophages, ${ }^{65,66}$ 


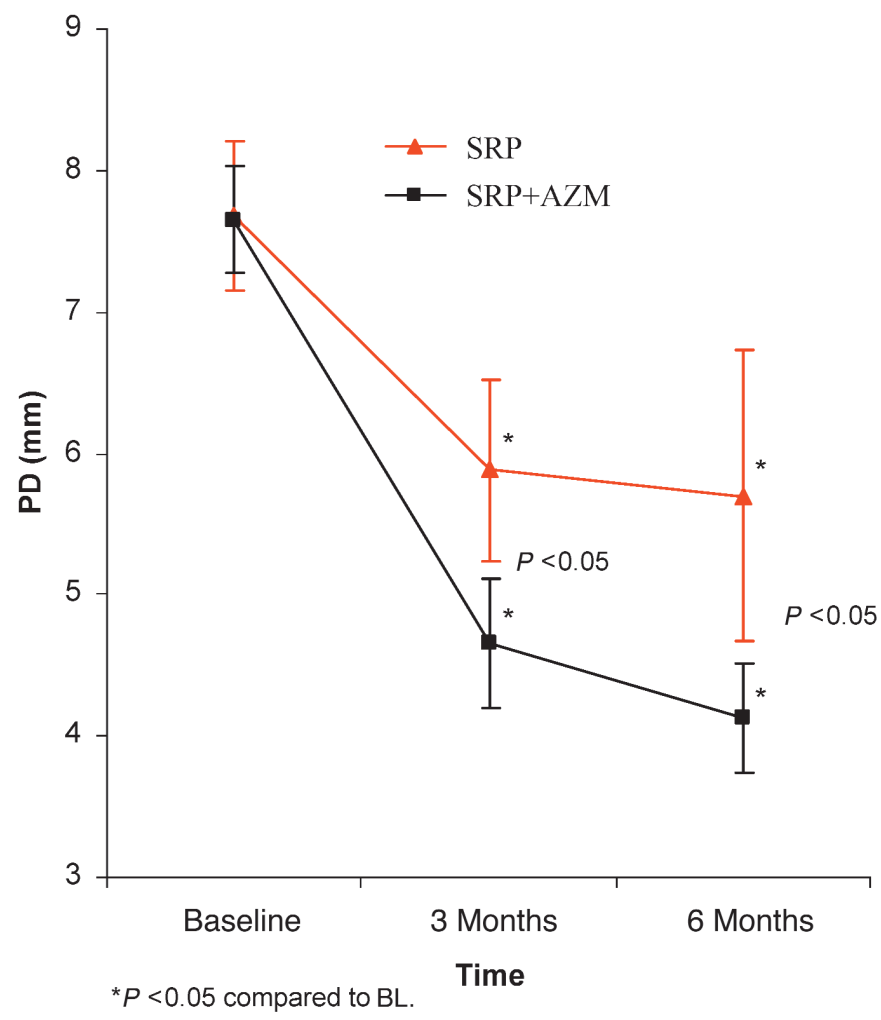

Figure 8.

Effect of AZM + SRP or SRP on PD for deep sites (PD $>6 \mathrm{~mm}$ ). Data expressed as per patient means \pm SE. $P<0.05$ represents a statistically significant difference between groups at months 3 and 6 .

fibroblasts, ${ }^{67}$ monocytes, ${ }^{68}$ and epithelial cells, ${ }^{69}$ which may explain the high level of azithromycin found in the infected tissues. ${ }^{62,63,70-72}$

The goal of this randomized controlled clinical trial was to explore the clinical, microbiological, and biochemical impact of AZM in periodontal healing compared with SRP alone. As expected, both groups showed clinical improvements in PD and CAL. Patients receiving SRP alone showed similar results to those achieved in previously reported clinical trials. $2,3,7,10,36,73,74$ These results were more pronounced for the AZM group and the difference was statistically significant, although at baseline, the mean PD and AL for the test group was statistically significantly greater, which may in part explain the better results found in this group.

In the present study, clinical efficacy was evaluated at sites stratified with respect to baseline PD. For shallow sites (PD $<4 \mathrm{~mm}$ ), control and test groups showed a reduction of 0.02 and $0.43 \mathrm{~mm}$, respectively, when compared to baseline. This is in agreement with studies reporting 0.03 to $0.23 \mathrm{~mm}$ of PD reduction with SRP. ${ }^{2,73,75,76}$ In the AZM group, a small but a statistically significant reduction was noted when compared to baseline. For PD of 4 to $6 \mathrm{~mm}$ an average of $1.0 \mathrm{~mm}$ and $1.7 \mathrm{~mm}$ of PD reduction was noted for the control

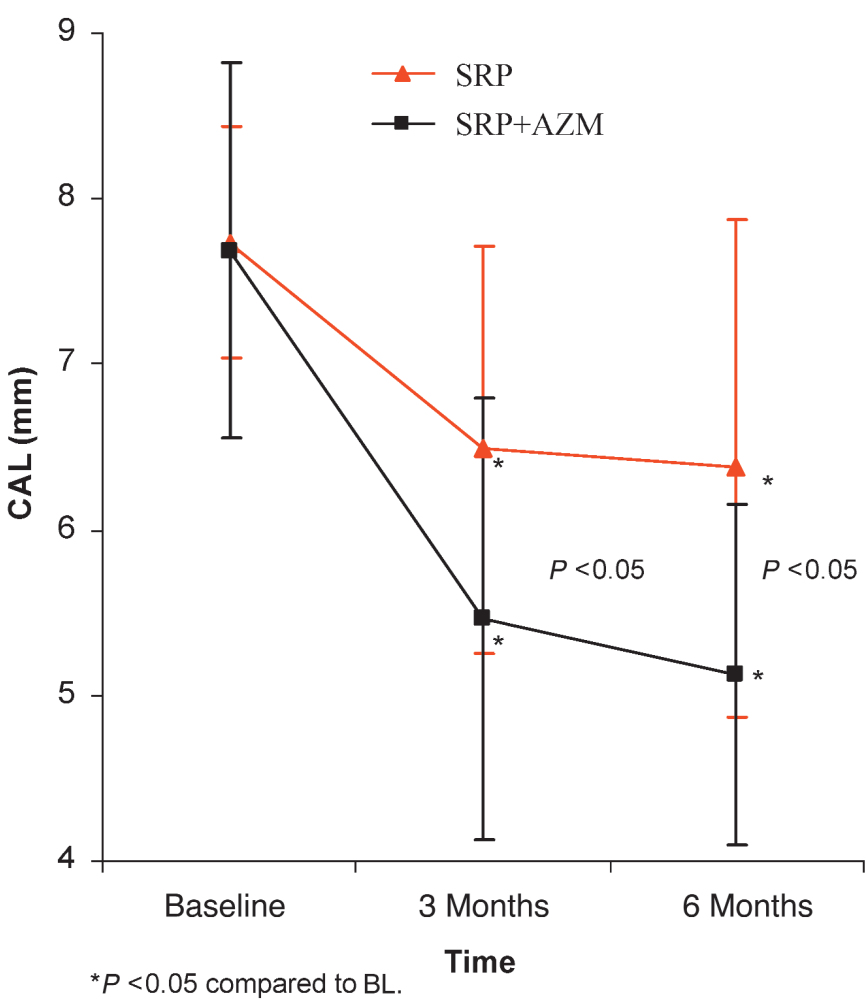

Figure 9.

Effect of AZM + SRP or SRP on CAL for deep sites (PD >6 mm). Data are expressed as per patient means \pm SE. $P<0.05$ represents $a$ statistically significant difference between groups at months 3 and 6 .

and test groups, respectively. Generally, SRP usually results in 0.71 to $1.26 \mathrm{~mm}$ of reduction in moderate pockets. $2,3,7,73-75$ The PD reduction in this smoking population for the control group was similar as previously reported ${ }^{9,10,15-21}$ and it was more marked and sustained for patients in the test group. These results may be considered above average even for a nonsmoking population. Several potential mechanisms could be used to explain the PD reduction seen with AZM therapy. They include: 1) good compliance with AZM therapy; 2) AZM therapy may promote more rapid wound maturation by rapid reduction of bacterial loads in the infected sites; 3 ) full mouth SRP performed in a maximum of 1 week might have reduced the cross infection potential and it probably contributes in part to the results obtained; 4 ) the fact that AZM maintains a high concentration in the inflammatory cells that are present in high concentration in periodontally-diseased soft tissues; 5) possible low bacterial resistance to AZM (this was not tested in this trial). In the deep PD (>6 mm), drug therapy group had a $3.52 \mathrm{~mm}$ PD reduction when compared to $1.98 \mathrm{~mm}$ PD reduction in the SRP control group. Other studies have reported 1.21 to $2.92 \mathrm{~mm}$ in PD reduction in deep pockets after SRP. ${ }^{2,73-76}$ The difference noted here was sustained throughout the 


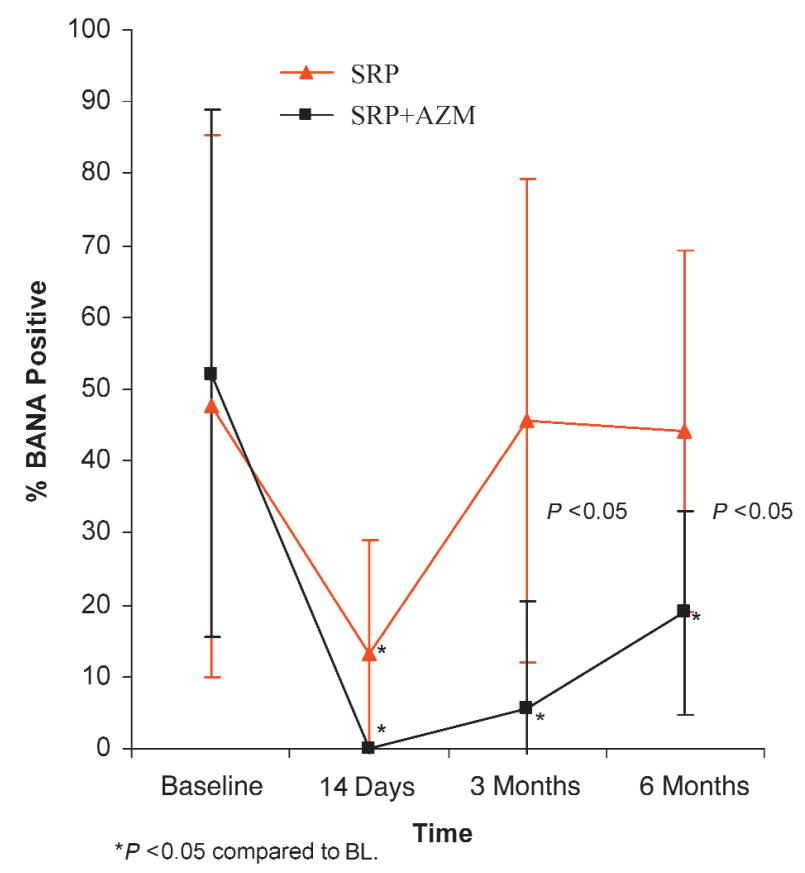

Figure 10.

Effect of AZM + SRP or SRP on the percentage of BANA positive sites. Data expressed as per patient percent of means \pm SE. $P<0.05$ indicates a statistically significant difference between groups at months 3 and 6 .

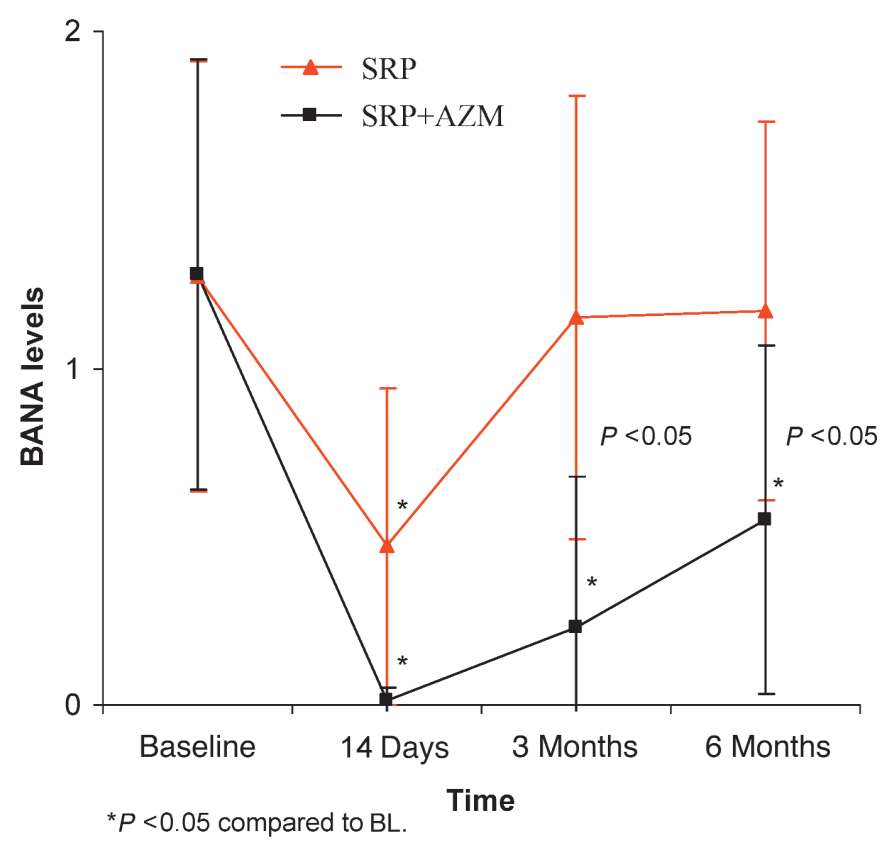

Figure II.

Effect of AZM + SRP or SRP on the mean BANA levels for all tested sites. Data expressed as per patient means \pm SE for the BANA level. $P<0.05$ indicates a statistically significant difference between groups at months 3 and 6 .

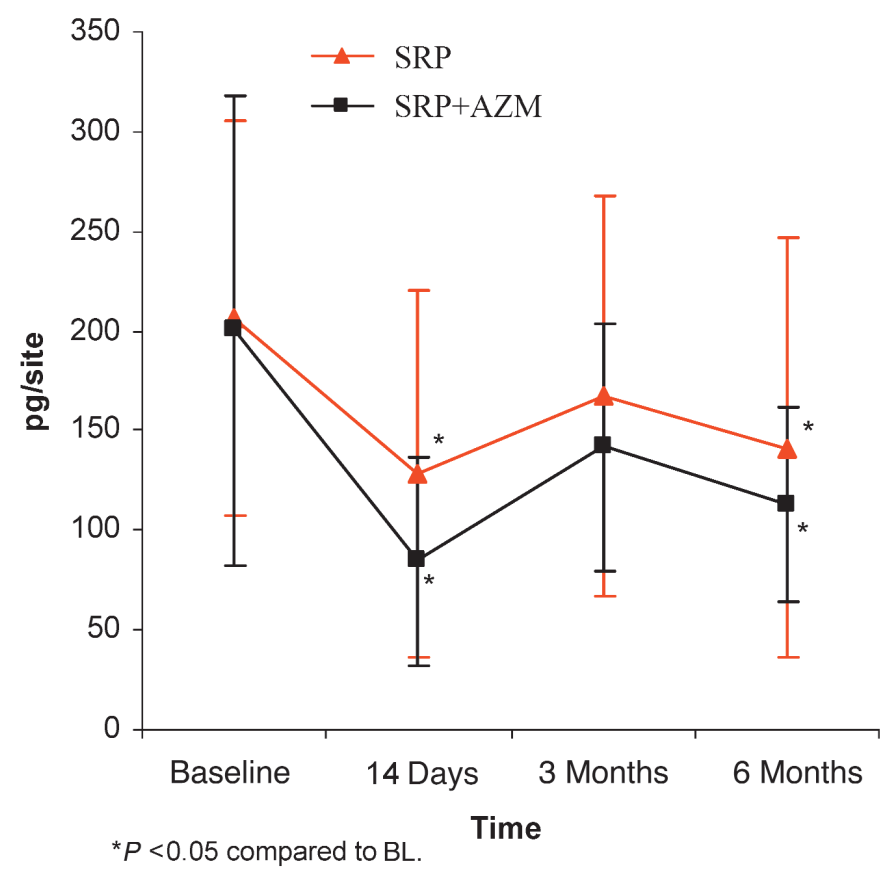

Figure I 2 .

Effect of AZM + SRP or SRP on the mean ICTP. Data expressed as per patient means \pm SE for the ICTP levels (pg/site). There were no statistically significant differences between groups.

study. However, it was not statistically significant. This is due to baseline variability that potentially reduced the difference observed.

Similar results were obtained when AL changes were analyzed. SRP in shallow sites is usually associated with attachment loss ranges from 0.3 to $0.89 \mathrm{~mm}, 7,75-77$ although in this study both groups showed a slight AL gain. The same AL gain trend was also observed for deeper PD sites, where AL changes were statistically significant for both groups when compared to baseline. This is in agreement with studies that have reported 0.47 to $1.59 \mathrm{~mm}$ of AL gain as a result of SRP therapy in sites with initial PD $>6 \mathrm{~mm}$. $^{2,3,73,75,77}$ As discussed regarding the PD changes, the results observed for the AL gain were very relevant and significantly higher when compared to a metronidazole study in smokers, which resulted in $0.55 \mathrm{~mm}$ of AL gain. ${ }^{78}$ This may be attributed to the above mentioned AZM mechanisms. However, an important aspect to consider is the difference in the attachment levels between groups at baseline noted in our study.

In this study the prevalence of sites with BOP was greater than in another published trial conducted on smokers with moderate to severe periodontitis. Preber and Bergstorm found a BOP prevalence of $27 \%$ and $40 \%$ for smokers and non-smokers with moderate to severe periodontal disease. ${ }^{17}$ The difference observed here could be explained by more severe periodontal destruction used in 
our study. Our data also revealed statistically significant BOP reduction from baseline for both groups, but there was no difference between them. This suggests that the results are more linked to mechanical therapy than with systemic AZM administration.

In the present study, $50 \%$ of the sampled sites were BANA positive. The reduction in the percent of BANA positive sites from baseline to 6 months was about 10 -fold higher for the test group. Both groups demonstrated reductions of BANA positive sites percentage at the 14-day evaluation; however, in the control group a rebound was observed. This may be attributed to the limitations of mechanical therapy since it did not eradicate BANA-positive bacteria in the periodontal tissues. In this situation, the application of AZM can be effective since high concentrations of this drug have been identified in the inflamed tissues. ${ }^{79}$ Although AZM helped to reduce microorganisms from baseline to 6 months, a trend of bacterial recolonization was noted in both groups. This is in agreement with Slots et al., ${ }^{80}$ who showed that a single episode of periodontal treatment including antibiotics immediately decreased the total number of subgingival organisms by 10 - to 100 -fold. However, several Gram-negative anaerobic species returned to pretreatment proportions after 3 to 6 months. ${ }^{80}$ These outcomes were further confirmed by other investigations. ${ }^{81,82}$ This observation may indicate that, in order to achieve long-standing microbiological and clinical results, readministration of antibiotic may be needed every 6 months. Future study in this area is needed to confirm this hypothesis.

For ICTP, our results showed a statistically significant mean reduction for both groups, but no significant differences between them. Longitudinal GCF ICTP levels reported in this study are similar to the ones in a previous study where initial reduction became less obvious at 3 months following SRP. ${ }^{83}$ This may be associated with the presence of inflammation as evidenced by the high percentage of BOP throughout the study period. On the other hand, the trend for increased GCF ICTP levels 3 months after SRP may be associated with the recurrence of periodontal disease that is known in smokers. ${ }^{10,22,84,85}$ If this is the case, it is understandable that biochemical mediator levels (such as ICTP) start to indicate disease recurrence signs before other clinical parameters. Furthermore, our data also demonstrated deeper pockets had higher ICTP levels, although a strong correlation between PD and ICTP levels was not found $(r=0.24)$. A similar conclusion was also reported by Palys and coworkers, ${ }^{86}$ who reported that GCF ICTP related modestly to clinical parameters. In addition, patients diagnosed with periodontitis had a 2 -fold increase in GCF ICTP levels compared to gingivitis patients and 30-fold higher levels than healthy patients. ${ }^{86}$
Within the limit of this study, it was concluded that the utilization of AZM in combination with SRP enhances the efficacy of non-surgical periodontal therapy in reducing pocket depth and improving attachment levels in smokers with moderate to advanced attachment loss.

\section{ACKNOWLEDGMENTS}

This work was partially supported by the University of Michigan Periodontal Graduate Student Research Fund. The drug was kindly donated by Pfizer, Inc., New York, New York. The authors thank Dr. Yi-Pin Tsao, graduate student at the University of Michigan School of Dentistry, for her excellent assistance during patient randomization.

\section{REFERENCES}

1. Lindhe J, Nyman S. The effect of plaque control and surgical pocket elimination on the establishment and maintenance of periodontal health. A longitudinal study of periodontal therapy in cases of advanced disease. J Clin Periodontol 1975;2:67-79.

2. Hill RW, Ramfjord SP, Morrison EC, et al. Four types of periodontal treatment compared over two years. J Periodontol 1981;52:655-662.

3. Ramfjord SP, Caffesse RG, Morrison EC, et al. Four modalities of periodontal treatment compared over five years. J Periodontal Res 1987;22:222-223.

4. Caffesse RG, Sweeney PL, Smith BA. Scaling and root planing with and without periodontal flap surgery. J Clin Periodontol 1986;13:205-210.

5. Rabbani GM, Ash MM Jr, Caffesse RG. The effectiveness of subgingival scaling and root planing in calculus removal. J Periodontol 1981;52:119-123.

6. Becker W, Becker BE, Caffesse R, et al. A longitudinal study comparing scaling, osseous surgery, and modified Widman procedures: Results after 5 years. J Periodontol 2001;72:1675-1684.

7. Knowles JW, Burgett FG, Nissle RR, et al. Results of periodontal treatment related to pocket depth and attachment level. Eight years. J Periodontol 1979;50:225-233.

8. Scabbia A, Cho KS, Sigurdsson TJ, et al. Cigarette smoking negatively affects healing response following flap debridement surgery. J Periodontol 2001;72:43-49.

9. Preber H, Bergstrom J. Effect of cigarette smoking on periodontal healing following surgical therapy. J Clin Periodontol 1990;17:324-328.

10. Preber $\mathrm{H}$, Bergstrom J. The effect of non-surgical treatment on periodontal pockets in smokers and non-smokers. $J$ Clin Periodontol 1986;13:319-323.

11. Grossi SG, Genco RJ, Machtei EE, et al. Assessment of risk for periodontal disease. II. Risk indicators for alveolar bone loss. J Periodontol 1995;66:23-29.

12. Haber J, Wattles J, Crowley M, et al. Evidence for cigarette smoking as a major risk factor for periodontitis. J Periodontol 1993;64:16-23.

13. Haffajee AD, Socransky SS. Relationship of cigarette smoking to attachment level profiles. J Clin Periodontol 2001;28:283-295.

14. Haffajee AD, Socransky SS. Relationship of cigarette smoking to the subgingival microbiota. J Clin Periodontol 2001;28:377-388.

15. Zambon JJ, Grossi SG, Machtei EE, et al. Cigarette smoking increases the risk for subgingival infection with periodontal pathogens. J Periodontol 1996;67(Suppl.): 1050-1054. 
16. Ah MK, Johnson GK, Kaldahl WB, et al. The effect of smoking on the response to periodontal therapy. J Clin Periodontol 1994;21:91-97.

17. Preber H, Bergstrom J. Occurrence of gingival bleeding in smoker and non-smoker patients. Acta Odontol Scand 1985;43:315-320.

18. Bain CA, Moy PK. The association between the failure of dental implants and cigarette smoking. Int J Oral Maxillofac Implants 1993;3:609-615.

19. Haffajee AD, Cugini MA, Dibart S, et al. The effect of SRP on the clinical and microbiological parameters of periodontal diseases. J Clin Periodontol 1997;24:324-34.

20. American Academy of Periodontology. Tobacco use and the periodontal patient (position paper). J Periodontol 1999;70:1419-1427.

21. Tonetti MS. Cigarette smoking and periodontal diseases: Etiology and management of disease. Ann Periodontol 1998;3:88-101.

22. Kaldahl WB, Johnson GK, Patil KD, et al. Levels of cigarette consumption and response to periodontal therapy. J Periodontol 1996;67:675-681.

23. Costabel $U$, Bross $\mathrm{KJ}$, Reuter C, et al. Alterations in immunoregulatory $\mathrm{T}$-cell subsets in cigarette smokers. A phenotypic analysis of bronchoalveolar and blood lymphocytes. Chest 1986;90:39-44.

24. MacFarlane GD, Herzberg MC, Wolff LF, et al. Refractory periodontitis associated with abnormal polymorphonuclear leukocyte phagocytosis and cigarette smoking. $J$ Periodontol 1992;63:908-913.

25. Johnson JD, Houchens DP, Kluwe WM, et al. Effects of mainstream and environmental tobacco smoke on the immune system in animals and humans: A review. Crit Rev Toxicol 1990;20:369-395.

26. Loesche WJ, Gusberti F, Mettraux G, et al. Relationship between oxygen tension and subgingival bacterial flora in untreated human periodontal pockets. Infect Immun 1983;42:659-667.

27. Mettraux GR, Gusberti FA, Graf H. Oxygen tension (pO2) in untreated human periodontal pockets. J Periodontol 1984;55:516-521.

28. Venditto MA. Therapeutic considerations: Lower respiratory tract infections in smokers. J Am Osteopath Assoc 1992;92:897-900;903-905.

29. Silverstein P. Smoking and wound healing. Am J Med 1992;93:22S-24S.

30. Raulin LA, McPherson JC 3rd, McQuade MJ, et al. The effect of nicotine on the attachment of human fibroblasts to glass and human root surfaces in vitro. J Periodontol 1988;59:318-325.

31. Hanes PJ, Schuster GS, Lubas S. Binding, uptake, and release of nicotine by human gingival fibroblasts. J Periodontol 1991;62:147-152.

32. Badersten A, Nilveus R, Egelberg J. Effect of nonsurgical periodontal therapy. III. Single versus repeated instrumentation. J Clin Periodontol 1984;11:114-124.

33. Hirschfeld L, Wasserman B. A long-term survey of tooth loss in 600 treated periodontal patients. J Periodontol 1978;49:225-237.

34. McFall WT Jr. Tooth loss in 100 treated patients with periodontal disease. A long-term study. J Periodontol 1982;53:539-549.

35. Haffajee AD, Socransky SS, Ebersole JL. Survival analysis of periodontal sites before and after periodontal therapy. J Clin Periodontol 1985;12:553-567.

36. Magnusson I, Clark WB, Low SB, et al. Effect of non-surgical periodontal therapy combined with adjunctive antibiotics in subjects with "refractory" periodontal disease. (I).
Clinical results. J Clin Periodontol 1989;16:647-653.

37. Colombo AP, Haffajee AD, Dewhirst FE, et al. Clinical and microbiological features of refractory periodontitis subjects. J Clin Periodontol 1998;25:169-180.

38. Kleinfelder JW, Muller RF, Lange DE. Bacterial susceptibility to amoxicillin and potassium clavulanate in advanced periodontitis patients not responding to mechanical therapy. J Clin Periodontol 2000;27:846-853.

39. Levy RM, Giannobile WV, Feres $M$, et al. The effect of apically repositioned flap surgery on clinical parameters and the composition of the subgingival microbiota: 12-month data. Int $J$ Periodontics Restorative Dent 2002;22:209-219.

40. Magnusson I, Marks RG, Clark WB, et al. Clinical, microbiological and immunological characteristics of subjects with "refractory" periodontal disease. J Clin Periodontol 1991;18:291-299.

41. Loesche WJ, Syed SA, Morrison EC, et al. Metronidazole in periodontitis. I. Clinical and bacteriological results after 15 to 30 weeks. J Periodontol 1984;55:325-335.

42. Collins JG, Offenbacher S, Arnold RR. Effects of a combination therapy to eliminate Porphyromonas gingivalis in refractory periodontitis. J Periodontol 1993;64:998-1007.

43. Socransky SS, Haffajee AD. The bacterial etiology of destructive periodontal disease: Current concepts. $J$ Periodontol 1992;63(Suppl.):322-331.

44. Socransky SS, Haffajee AD, Cugini MA, et al. Microbial complexes in subgingival plaque. J Clin Periodontol 1998;25:134-144.

45. Slots J, van Winkelhoff AJ. Antimicrobial therapy in periodontics. J Calif Dent Assoc 1993;21:51-56.

46. Drisko $\mathrm{CH}$. Non-surgical pocket therapy: Pharmacotherapeutics. Ann Periodontol 1996;1:491-566.

47. Hanes PJ, Purvis JP. Local anti-infective therapy: Pharmacological agents. A systematic review. Ann Periodontol 2003;8:79-98.

48. Haffajee AD, Socransky SS, Gunsolley JC. Systemic anti-infective therapy: Pharmacological agents. A systematic review. Ann Periodontol 2003;8:115-181.

49. Sanz M, Herrera D. Antibiotic and Antimicrobial Use in Dental Practice, 2nd ed. Chicago: Quintessence Books; 2001:33-52.

50. Sefton AM, Maskell JP, Beighton D, et al. Azithromycin in the treatment of periodontal disease. Effect on microbial flora. J Clin Periodontol 1996;23:998-1003.

51. Pajukanta R, Asikainen S, Saarela $M$, et al. In vitro activity of azithromycin compared with that of erythromycin against Actinobacillus actinomycetemcomitans. Antimicrob Agents Chemother 1992;36:1241-1243.

52. Pajukanta R. In vitro antimicrobial susceptibility of Porphyromonas gingivalis to azithromycin, a novel macrolide. Oral Microbiol Immunol 1993;8:325-326.

53. Powers JL. Properties of azithromycin that enhance the potential for compliance in children with upper respiratory tract infections. Pediatr Infect Dis $J$ 1996;15 (Suppl. 9):S30-S37.

54. Gladue RP, Bright GM, Isaacson RE, et al. In vitro and in vivo uptake of azithromycin (CP-62,993) by phagocytic cells: Possible mechanism of delivery and release at sites of infection. Antimicrob Agents Chemother 1989;33:277-282.

55. Filatova NA, Kuznetsov EA, Dmitrieva LA, et al. The prospects for using the new macrolide antibiotic azithromycin (Sumamed) in the combined treatment of periodontitis (in Russian). Stomatologiia 1995;74:12-15.

56. Loesche WJ, Kazor CE, Taylor GW. The optimization of the BANA test as a screening instrument for gingivitis 
among subjects seeking dental treatment. J Clin Periodontol 1997;24:718-726.

57. Giannobile WV, Lynch SE, Denmark RG, et al. Crevicular fluid osteocalcin and pyridinoline cross-linked carboxyterminal telopeptide of type I collagen (ICTP) as markers of rapid bone turnover in periodontitis. A pilot study in beagle dogs. J Clin Periodontol 1995;22:903-910.

58. Varvara G, D'Arcangelo $C$. The evaluation of the clinical efficacy and tolerance of azithromycin in odontostomatological infections. Minerva Stomatol 1998;47:57-62.

59. Sasaki J, Kaneko A, Karakida K, et al. Comparative clinical study of azithromycin with tosufloxacin tosilate in the treatment of acute odontogenic infection. Jpn $J$ Antibiot 1995;48:1093-1118.

60. Malizia T, Batoni G, Ghelardi E, et al. Interaction between piroxicam and azithromycin during distribution to human periodontal tissues. J Periodontol 2001;72:1151-1156.

61. Malizia T, Tejada MR, Ghelardi E, et al. Periodontal tissue disposition of azithromycin. J Periodontol 1997;68:12061209.

62. Stein GE, Havlichek DH. The new macrolide antibiotics. Azithromycin and clarithromycin. Postgrad Med 1992;92: 269-272;277-282.

63. Foulds G, Shepard RM, Johnson RB. The pharmacokinetics of azithromycin in human serum and tissues. $J$ Antimicrob Chemother 1990;25(Suppl. A):73-82.

64. Rodriguez-Bano J, Pascoal A, Ballesta S, et al. Penetration of azithromycin in human neutrophils: Influence in production of hydrogen peroxide (in Spanish). Enferm Infecc Microbiol Clin 1997;15:196-199.

65. McDonald PJ, Pruul H. Phagocyte uptake and transport of azithromycin. Eur J Clin Microbiol Infect Dis 1991;10: 828-33.

66. Lode H. The pharmacokinetics of azithromycin and their clinical significance. Eur J Clin Microbiol Infect Dis 1991; 10:807-812.

67. Gladue RP, Snider ME. Intracellular accumulation of azithromycin by cultured human fibroblasts. Antimicrob Agents Chemother 1990;34:1056-1060.

68. Wildfeuer A, Laufen H, Muller-Wening D, et al. Interaction of azithromycin and human phagocytic cells. Uptake of the antibiotic and the effect on the survival of ingested bacteria in phagocytes. Arzneimittelforschung 1989;39: 755-758.

69. Raulston JE. Pharmacokinetics of azithromycin and erythromycin in human endometrial epithelial cells and in cells infected with Chlamydia trachomatis. J Antimicrob Chemother 1994;34:765-776.

70. Ballow CH, Amsden GW. Azithromycin: The first azalide antibiotic. Ann Pharmacother 1992;26:1253-1261.

71. Baughman RP, DeSante KA, Lanier TL, et al. The penetration of dirithromycin into bronchoalveolar lavage fluid and alveolar macrophages. J Antimicrob Chemother 1994;33:1045-1050.

72. Mor N, Vanderkolk J, Heifets L. Accumulation of clarithromycin in macrophages infected with Mycobacterium avium. Pharmacotherapy 1994;14:100-104.

73. Kaldahl WB, Kalkwarf KL, Patil KD, et al. Evaluation of four modalities of periodontal therapy. Mean probing depth, probing attachment level, and recession changes. $J$ Periodontol 1988;59:783-793.

74. Badersten A, Nilveus R, Egelberg J. Effect of nonsurgical periodontal therapy. II. Severely advanced periodontitis. $J$ Clin Periodontol 1984;11:63-76.

75. Hammerle CH, Joss A, Lang NP. Short-term effects of initial periodontal therapy (hygienic phase). J Clin Periodontol 1991;18:233-239.
76. Morrison EC, Ramfjord SP, Hill RW. Short-term effects of initial, nonsurgical periodontal treatment (hygienic phase). J Clin Periodontol 1980;7:199-211.

77. Claffey N, Loos B, Gantes B, et al. The relative effects of therapy and periodontal disease on loss of probing attachment after root debridement. J Clin Periodontol 1988;15:163-169.

78. Palmer RM, Matthews JP, Wilson RF. Non-surgical periodontal treatment with and without adjunctive metronidazole in smokers and non-smokers. J Clin Periodontol 1999;26:158-163.

79. Blandizzi C, Malizia T, Lupetti A, et al. Periodontal tissue disposition of azithromycin in patients affected by chronic inflammatory periodontal diseases. J Periodontol 1999;70:960-966.

80. Slots J, Mashimo P, Levine MJ, et al. Periodontal therapy in humans. I. Microbiological and clinical effects of a single course of periodontal scaling and root planing, and of adjunctive tetracycline therapy. J Periodontol 1979;50: 495-509.

81. Sbordone L, Ramaglia L, Gulletta E, et al. Recolonization of the subgingival microflora after scaling and root planing in human periodontitis. J Periodontol 1990;61:579-584.

82. Lavanchy DL, Bickel M, Baehni PC. The effect of plaque control after scaling and root planing on the subgingival microflora in human periodontitis. J Clin Periodontol 1987;14:295-299.

83. Al-Shammari KF, Giannobile WV, Aldredge WA, et al. Effect of non-surgical periodontal therapy on C-telopeptide pyridinoline cross-links (ICTP) and interleukin-1 levels. J Periodontol 2001;72:1045-1051.

84. Grossi SG, Skrepcinski FB, DeCaro T, et al. Response to periodontal therapy in diabetics and smokers. J Periodontol 1996;67(Suppl.):1094-1102.

85. Preber H, Linder L, Bergstrom J. Periodontal healing and periopathogenic microflora in smokers and non-smokers. $J$ Clin Periodontol 1995;22:946-952.

86. Palys MD, Haffajee AD, Socransky SS, Giannobile WV. Relationship between C-telopeptide pyridinoline crosslinks (ICTP) and putative periodontal pathogens in periodontitis. J Clin Periodontol 1998;25:865-871.

Correspondence: Dr. Hom-Lay Wang, Graduate Periodontics, University of Michigan, School of Dentistry, 1011 N. University Ave., Ann Arbor, MI 48109-1078. Fax: 734/763-5503; e-mail: homlay@umich.edu.

Accepted for publication July 2, 2004. 